\title{
Ternary nanocomposites of reduced graphene oxide, polyaniline and hexaniobate: hierarchical architecture and high polaron formation
}

\author{
Claudio H. B. Silva ${ }^{* 1,2,3}$, Maria lliut ${ }^{2}$, Christopher Muryn ${ }^{4}$, Christian Berger², \\ Zachary Coldrick $^{5}$, Vera R. L. Constantino ${ }^{1}$, Marcia L. A. Temperini ${ }^{1}$ \\ and Aravind Vijayaraghavan ${ }^{2}$
}

\section{Full Research Paper}

\section{Address:}

${ }^{1}$ Department of Fundamental Chemistry, Institute of Chemistry, University of São Paulo, Av. Prof. Lineu Prestes 748, São Paulo 05508-000, Brazil, ${ }^{2}$ School of Materials and National Graphene Institute, The University of Manchester, Booth St E, Manchester M13 9PL, United Kingdom, ${ }^{3}$ present address: Department of Physical Chemistry, Institute of Chemistry, Federal University of Bahia, Rua Barão de Jeremoabo, 147, Salvador 40170-115, Brazil, ${ }^{4}$ School of Chemistry and Photon Science Institute, The University of Manchester, Alan Turing Building, Oxford Rd, Manchester M13 9PY, United Kingdom and ${ }^{5}$ School of Electrical and Electronic Engineering, The University of Manchester, Sackville Street Building, Manchester M1 3BB, United Kingdom

Email:

Claudio H. B. Silva* - chbsilva@ufba.br

* Corresponding author

Keywords:

graphene oxide; hexaniobate; polyaniline; Raman spectroscopy; secondary doping

\begin{abstract}
Beilstein J. Nanotechnol. 2018, 9, 2936-2946. doi:10.3762/bjnano.9.272
\end{abstract}

Received: 16 August 2018

Accepted: 30 October 2018

Published: 26 November 2018

This article is part of the thematic issue "Advanced hybrid nanomaterials". Guest Editor: F. Leroux

(C) 2018 Silva et al.; licensee Beilstein-Institut. License and terms: see end of document.

\footnotetext{
Abstract

Nanostructured systems, such as nanocomposites, are potential materials for usage in different fields since synergistic effects of their components at the nanoscale domain may improve physical/chemical properties when compared to individual phases. We report here the preparation and characterisation of a new nanocomposite composed of polyaniline (PANI), reduced graphene oxide (rGO) and hexaniobate (hexNb) nanoscrolls. Atomic force microscopy images show an interesting architecture of rGO flakes coated with PANI and decorated by hexNb. Such features are attributed to the high stability of the rGO flakes prepared at room temperature. Detailed characterisation by X-ray photoelectron and Raman spectroscopies indicates an intermediate reduction degree for the rGO component and high doping degree of the PANI chains compared to the neat polymer. The latter feature can be attributed to cooperative effects of PANI chains with rGO flakes and hexNb nanoscrolls, which promote conformational changes of the polymer backbone (secondary doping). Spectroscopic and electrochemistry data indicate a synergetic effect on the ternary nanocomposite, which is attributed to interactions between the components resulting from the morphological aspects. Therefore, the new
} 
nanocomposite presents promising properties for development of new materials in the film form on substrates for sensing or corrosion protection for example.

\section{Introduction}

Nanostructured systems, such as nanocomposites, are potential materials for usage as electrochemical (bio)sensors for analytical purposes, electronics, energy storage devices and corrosion protection because the synergistic effects of their components at the nanoscale range may improve physical/chemical properties when compared to individual phases or enable new technological applications [1-3]. For instance, ternary nanocomposites (conducting polymers, metal oxides and carbon-based materials) exhibit improved energy and power densities, improved stabilities upon charge/discharge cycles [4], and higher electrocatalytic activity in the quantification of chemical species compared to the isolated components [5].

In earlier studies, some of us reported the preparation of binary nanocomposites of polyaniline (PANI) and hexaniobate (hexNb) nanoscrolls by layer-by-layer assembly and the characterisation by spectroscopic and cyclic voltammetry/spectroelectrochemical techniques [6]. The inorganic phase induces a secondary doping of the conductor polymer. In another work [7], Raman and EPR spectra also revealed that a PANI/hexNb nanocomposite prepared by the self-assembly approach exhibits a higher conversion of bipolaronic to polaronic segments compared to the neat polymer and a superior thermal stability (the doped form of PANI is observed even after heating at $150{ }^{\circ} \mathrm{C}$ for $90 \mathrm{~min}$ ).

The literature has shown that PANI and reduced graphene oxide (rGO) show enhanced properties when combined at the nanoscale domain and applied, for instance, as supercapacitors, sensing materials, solar cells, electrochromic devices, anticorrosion coatings or as materials for carbon dioxide capture [8]. The layered inorganic phase offers a high surface area for PANI deposition and increases its thermal stability with regard to decomposition, which is assigned to strong interactions between the two components [8]. Besides, rGO presents defects and functional groups on its surfaces that are sites for catalysis or sorption of substrates [9]. Considering the confirmed synergistic effects of PANI/hexNb and PANI/rGO binary nanocomposites, materials comprising all three components can be expected to show improved properties.

Since its discovery in 2004, graphene has been proposed for a wide range of applications due to its supreme values of specific surface area, electronic mobility, thermal and electrical conductivities and elastic modulus $[10,11]$. Graphene oxide (GO) is a graphene derivative that has also attracted great scientific interest due to its better processability and scalable production in comparison with pristine graphene [12]. The great chemical versatility of GO is mostly attributed to its complex structure, composed of 2D carbon layers with several oxygen-containing groups, such as hydroxy, epoxy, carbonyl and carboxyl, as schematically shown in Figure 1a [12,13]. Moreover, stable aqueous dispersions containing large GO flakes (above $20 \mu \mathrm{m}$ ) can be prepared [14]. For some applications, the restoration of the hexagonal carbon lattice (removal of functional groups) may be required and this process is performed by thermal or chemical reduction of GO, resulting in reduced graphene oxide ( $\mathrm{rGO}$ ) in which some of the properties of graphene are almost recovered, such as mechanical resistance and thermal and electrical conductivities [15-17].

Polyaniline (PANI) is a conducting polymer that has shown promising properties for the development of materials for different fields such as chemical sensing $[18,19]$, memory devices $[20,21]$ and energy storage $[22,23]$. As schematically shown in Figure 1b, the conducting form of PANI, the emeraldine salt (PANI-ES) contains two species: unpaired spin segments, the polarons (also known as radical cations); and paired spin segments, the bipolarons (also known as dications) [24,25]. The combination of PANI and inorganic materials at the nanoscale has shown interesting results for the preparation of nanocomposites that exhibit improved electrochemical, mechanical or thermal behaviour $[8,26,27]$.

Hexaniobate (hexNb) is a semiconducting metal oxide composed of negatively charged layers of $\left[\mathrm{NbO}_{6}\right]$ octahedral units and interlayer cations, such as potassium ions (precursor form $\mathrm{K}_{4} \mathrm{Nb}_{6} \mathrm{O}_{17}$ ) and protons (acidic form $\mathrm{H}_{2} \mathrm{~K}_{2} \mathrm{Nb}_{6} \mathrm{O}_{17}$ ) $[28,29]$. Due to their high acidic surfaces, protonic niobates and titanoniobates have been reported as promising solid acid catalysts for various chemical reactions [30,31]. Moreover, hexaniobate can be exfoliated by treatment with a number of species such as $n$-alkylamines and tetra(n-alkyl)ammonium hydroxides, giving rise to colloidal dispersions of nanoparticles of different morphologies such as nanosheets and nanoscrolls [32,33]. As reported previously [6], the treatment of $\mathrm{H}_{2} \mathrm{~K}_{2} \mathrm{Nb}_{6} \mathrm{O}_{17}$ with tetra( $n$-butyl)ammonium hydroxide (TBAOH) is an efficient method to produce dispersions of protonic hexNb nanoscrolls (schematised in Figure 1c). Moreover, strong interactions of PANI chains with acidic surfaces of $\mathrm{H}_{2} \mathrm{~K}_{2} \mathrm{Nb}_{6} \mathrm{O}_{17}$ may dramati- 
(a)

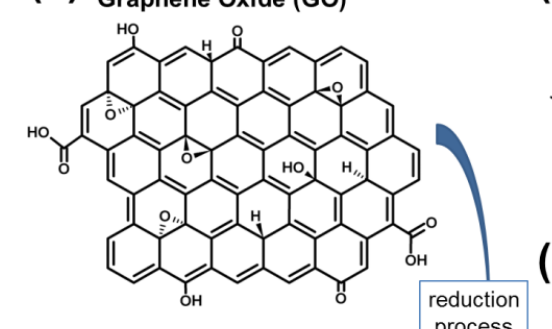

Reduced Graphene Oxide (rGO)

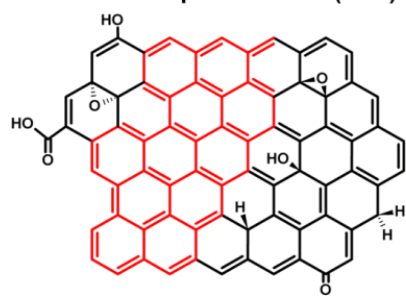

(b)

Emeraldine salt Polyaniline (doped form) (c) process<smiles>Cc1ccc(Nc2ccc([NH2+]c3ccc(Nc4ccc([NH2+]c5ccc(Nc6ccc(Nc7ccc([NH+](C)C)cc7)cc6)cc5)cc4)cc3)cc2)cc1</smiles>

C) Hexaniobate

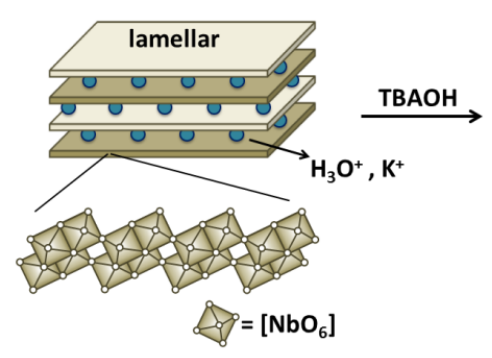

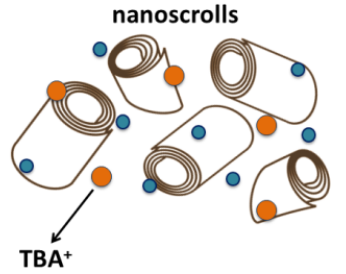

Figure 1: Schematic representation of (a) graphene oxide and reduced graphene oxide structures, (b) polaron and bipolaron segments of emeraldine salt polyaniline (doped form), and (c) hexaniobate in layered and nanoscroll morphologies. TBAOH: tetra( $n$-butyl)ammonium hydroxide, TBA ${ }^{+}$: tetra( $n$ butyl)ammonium cation.

cally affect the doping state of the polymeric chains [6,7], which is an interesting feature regarding applications of PANIbased materials.

In this paper we report the development of a new nanocomposite, with interesting nanostructured features, composed of reduced graphene oxide, polyaniline and hexaniobate, as well as its spectroscopic and textural characterisation.

\section{Results and Discussion}

$\mathrm{GO}$ reduction at high temperatures (typically above $90{ }^{\circ} \mathrm{C}$ ) results in the aggregation of the material due to restacking of the hydrophobic rGO layers [34,35]. This is a drawback in the preparation of rGO nanocomposites because phase segregation and/or composition heterogeneity will occur in the final materials. Although it is well known that high reaction temperatures are important for the degree of reduction of the resulting $\mathrm{rGO}$, samples prepared at room temperature $\left(25^{\circ} \mathrm{C}\right)$ using longer reaction times ( 7 days) may present satisfactory properties for nanocomposites. To obtain stable mixture of the components and optimize the interaction between them, graphene oxide reduction was performed at diluted conditions with hydrazine at low temperature (see Experimental section). The resulting dispersions of rGO-25 and rGO/PANI nanocomposites are remarkably stable (see Supporting Information File 1), more so than sample rGO-80. This indicates that the nanocomposites may exhibit low compositional heterogeneity and possibly strong interactions (such as electrostatic and $\pi-\pi$ interactions) between their components.
The morphological characterisation of $\mathrm{rGO}-25, \mathrm{rGO} / \mathrm{PANI}$ and $\mathrm{rGO} / \mathrm{PANI} / \mathrm{hexNb}$ samples was carried out by atomic force microscopy, as shown in Figure 2. AFM images of the rGO-25 sample show particles of well-defined edges and size ranging from 5 to $25 \mu \mathrm{m}$. The height profile (Figure 2, right column) shows thickness of ca. $1.0 \mathrm{~nm}$ and a surface roughness (RMS) of $0.24 \mathrm{~nm}$ for the rGO flake. These results clearly indicate the presence of smooth monolayer rGO particles, which are partially restacked when deposited on the $\mathrm{Si} / \mathrm{SiO}_{2}$ substrate. The AFM images of the rGO/PANI nanocomposite show similar flake dimensions (ca. $25 \mu \mathrm{m}$ ) as the rGO-25 sample, and no granular particles were observed, as reported for PANI aggregates [36]. On the other hand, this nanocomposite presents several creases and folds and, more interestingly, shows higher flake thickness and higher surface roughness (ca. 10 and ca. $4.0 \mathrm{~nm}$, respectively). These results clearly indicate that the deposition of PANI on rGO flakes induces an increase of the surface heterogeneity. Analogously, the AFM images of rGO/ $\mathrm{PANI} / \mathrm{hexNb}$ also indicate the presence of large flakes in the nanocomposite and, as shown by the $5 \mu \mathrm{m}$ scan-size image (and corresponding height profile), the flake thickness and surface roughness are ca. 19 and ca. $7.2 \mathrm{~nm}$, respectively. These results clearly indicate that the surface heterogeneity of the ternary nanocomposite is even higher than that of $\mathrm{rGO} / \mathrm{PANI}$, probably due to the presence of hexaniobate nanoparticles (nanoscrolls) on the rGO/PANI flakes.

For further description of the rGO/PANI/hexNb nanocomposite morphology, Figure 3 presents the AFM image of the hybrid 

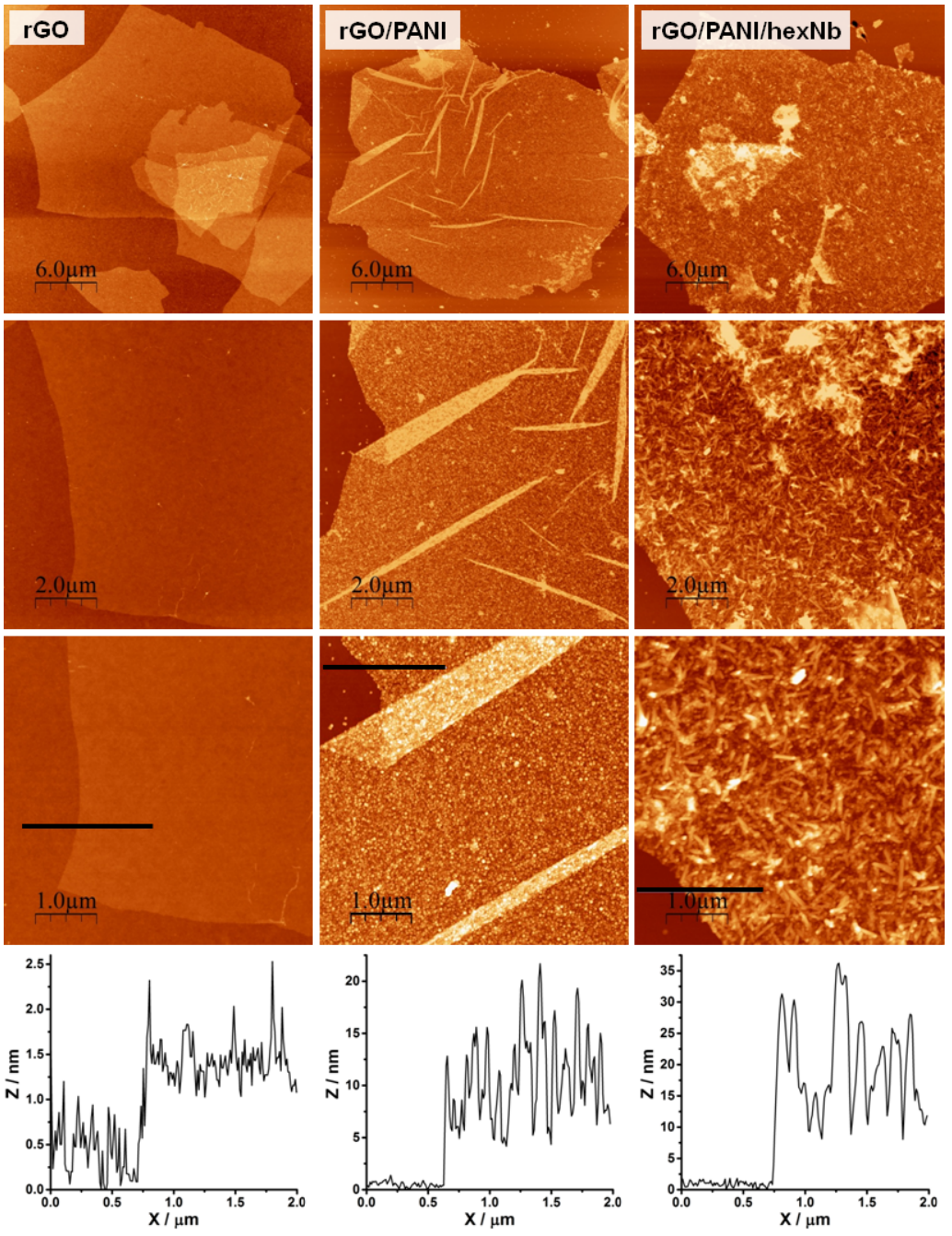

Figure 2: AFM images of rGO-25 sample, and rGO/PANI and rGO/PANI/hexNb nanocomposites at different scan sizes ( 30,10 and $5 \mu \mathrm{m})$, and height profiles (for the $5 \mu \mathrm{m}$ scan size images).

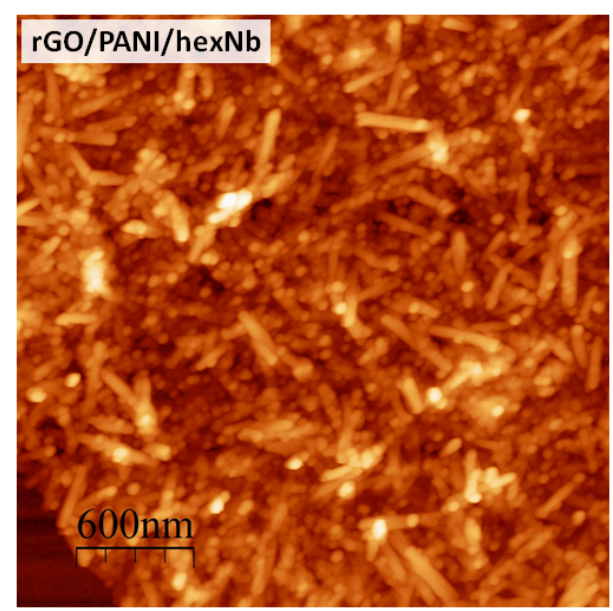

Figure 3: AFM images of rGO/PANI/hexNb nanocomposite at $3 \mu \mathrm{m}$ scan size. material at $3 \mu \mathrm{m}$ scan size. Figure 3 shows that the particles on the surface of $\mathrm{rGO} / \mathrm{PANI} / \mathrm{h}$ exNb exhibit a scroll-like shape (high aspect ratio), which is very similar to well-described hexNb nanoscrolls $[7,37,38]$. These results show the interesting hierarchical architecture of the ternary nanocomposite of rGO flakes coated with PANI and decorated by hexNb nanoscrolls.

To analyse the reduction of graphene oxide under the present conditions, GO and rGO samples were characterised by XPS spectroscopy. High-resolution XPS spectra can also provide information on the reduction degree of $\mathrm{GO}$, since $\mathrm{C} 1$ s core level photoelectrons present slightly different binding energies depending on the environment of the carbon atoms. Figure 4 shows the high-resolution XPS spectra at the $\mathrm{C} 1 \mathrm{~s}$ core level for $\mathrm{GO}$ and rGO samples prepared by reactions at $25^{\circ} \mathrm{C}$ for 7 days and at $80{ }^{\circ} \mathrm{C}$ for $3 \mathrm{~h}$ (rGO-25 and $\mathrm{rGO}-80$, respectively). XPS spectra of GO and rGO-25 consist mainly of two asymmetric 

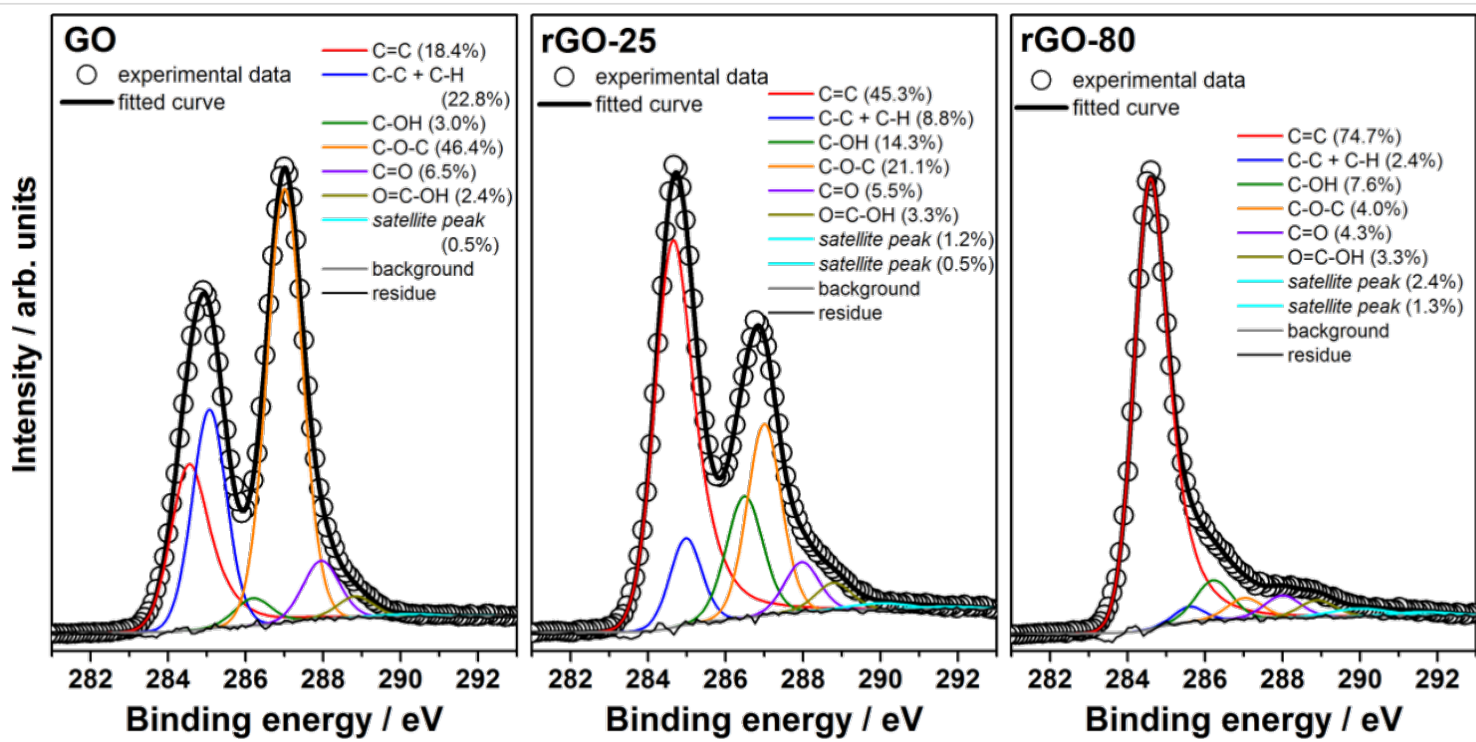

Figure 4: XPS spectra at the $\mathrm{C} 1 \mathrm{~s}$ core level of GO and rGO samples prepared by reactions at $25^{\circ} \mathrm{C}$ for 7 days or at $80{ }^{\circ} \mathrm{C}$ for $3 \mathrm{~h}(\mathrm{rGO}-25$ and rGO-80, respectively).

and highly overlapping peaks (maxima at ca. 285 and ca. $287 \mathrm{eV}$ ). The comparison of these spectra clearly shows the increase of relative intensity of the low-binding energy peak upon reduction. This is attributed to the partial recovery of the $\mathrm{sp}^{2}$-hybridized carbons in the graphene structure, since pristine graphite presents only an asymmetric peak at ca. $284 \mathrm{eV}$ (carbon atoms in $\mathrm{sp}^{2}$ environment) [39-41]. The curve fitting of the C 1s spectra, also presented in Figure 4, can provide detailed information on the oxygen-containing groups, since these groups induce different environments for the carbon atoms and, consequently, their corresponding $\mathrm{C} 1 \mathrm{~s}$ photoelectrons present slightly different binding energies [34,39,40,42-51]. The comparison of the curve fitting for GO and $\mathrm{rGO}-25$ shows the increase of the contribution from $\mathrm{sp}^{2}$ carbons $(\mathrm{C}=\mathrm{C})$ and hydroxy groups $(\mathrm{C}-\mathrm{OH})$ upon reduction, and the decrease of $\mathrm{sp}^{3}$ carbons $(\mathrm{C}-\mathrm{C}+\mathrm{C}-\mathrm{H})$ and epoxy groups $(\mathrm{C}-\mathrm{O}-\mathrm{C})$. These results are in good agreement with the literature and indicate the recovery of the $\mathrm{sp}^{2}$ carbon atoms from the $\mathrm{sp}^{3}$ carbon atoms and epoxy groups, and the conversion of some epoxy to hydroxy groups $[28,45,46,48]$. In contrast, $\mathrm{rGO}-80$ presents a dramatic change in the $\mathrm{C} 1 \mathrm{~s}$ spectral profile, evidenced by an intense peak at ca. $284 \mathrm{eV}$ and a weak shoulder at $285-290 \mathrm{eV}$. The comparison of the curve fitting for this sample and rGO-25 shows a significant increase of the contribution from the $\mathrm{sp}^{2}$ carbon atoms and decrease of the contribution from $\mathrm{sp}^{3}$ carbon atoms, hydroxy and epoxy groups. These features are very similar to data reported in literature for chemically reduced GO $[34,39,42-51]$ and indicate a high degree of reduction of the rGO-80 sample. This also points out the very important role of the temperature on the recovery of the $\mathrm{sp}^{2}$ carbon network in graphene oxide.
Analogously to C 1s, XPS spectra at the N 1s core level can be discussed in detail and provide interesting structural information on the rGO/PANI and $\mathrm{rGO} / \mathrm{PANI} /$ hexNb nanocomposites. In the present study, the $\mathrm{N} 1 \mathrm{~s}$ peaks are mostly from nitrogencontaining groups of PANI, the amine, imine or charged nitrogen sites (from polarons or bipolarons) of the polymeric chains [52-55]. Therefore, XPS spectroscopy provides important information on the oxidation and doping states of the polymer in PANI-based materials. Figure 5 shows XPS spectra at the $\mathrm{N} 1 \mathrm{~s}$ core level of PANI and $\mathrm{rGO} / \mathrm{PANI}$ and $\mathrm{rGO} / \mathrm{PANI} /$ hexNb nanocomposites, and the respective curve fitting results. The $\mathrm{N}$ 1s peak of PANI-based materials is dominated by an amine (-NH-)-related component at ca. $399 \mathrm{eV}$, but also shows components of quinone $(=\mathrm{N}-)$, polaron $\left(-\mathrm{N}^{\bullet+} \mathrm{H}-\right)$ and bipolaron $\left(=\mathrm{N}^{+} \mathrm{H}-\right)$ groups at ca. 398 , ca. 401 and ca. $402 \mathrm{eV}$, respectively. The comparison of spectral data for PANI and $\mathrm{rGO} / \mathrm{PANI}$ in Figure 5 shows that the relative contributions of polarons and bipolarons are higher in the nanocomposite. These results indicate that PANI chains present a higher doping state in the presence of rGO flakes. XPS data for the $\mathrm{rGO} / \mathrm{PANI} / \mathrm{hexNb}$ nanocomposite clearly shows a significant increase in the relative intensity of the peak with higher biding energy, attributed to polarons and bipolarons. Fitting results show that relative contributions of polarons increase from $18.3 \%$ in PANI and $23.0 \%$ in $\mathrm{rGO} / \mathrm{PANI}$ to $34.0 \%$ in the ternary nanocomposite. Also, relative contributions of bipolarons increase from $7.1 \%$ in PANI and $8.6 \%$ in $\mathrm{rGO} / \mathrm{PANI}$ to $11.3 \%$ in the $\mathrm{rGO} / \mathrm{PANI} /$ hexNb nanocomposite. These results clearly indicate that hexNb nanoparticles also play an important role to the increase of the doping state of PANI. More interestingly, fitting results indicate that the ratio between polarons and bipolarons is higher for 

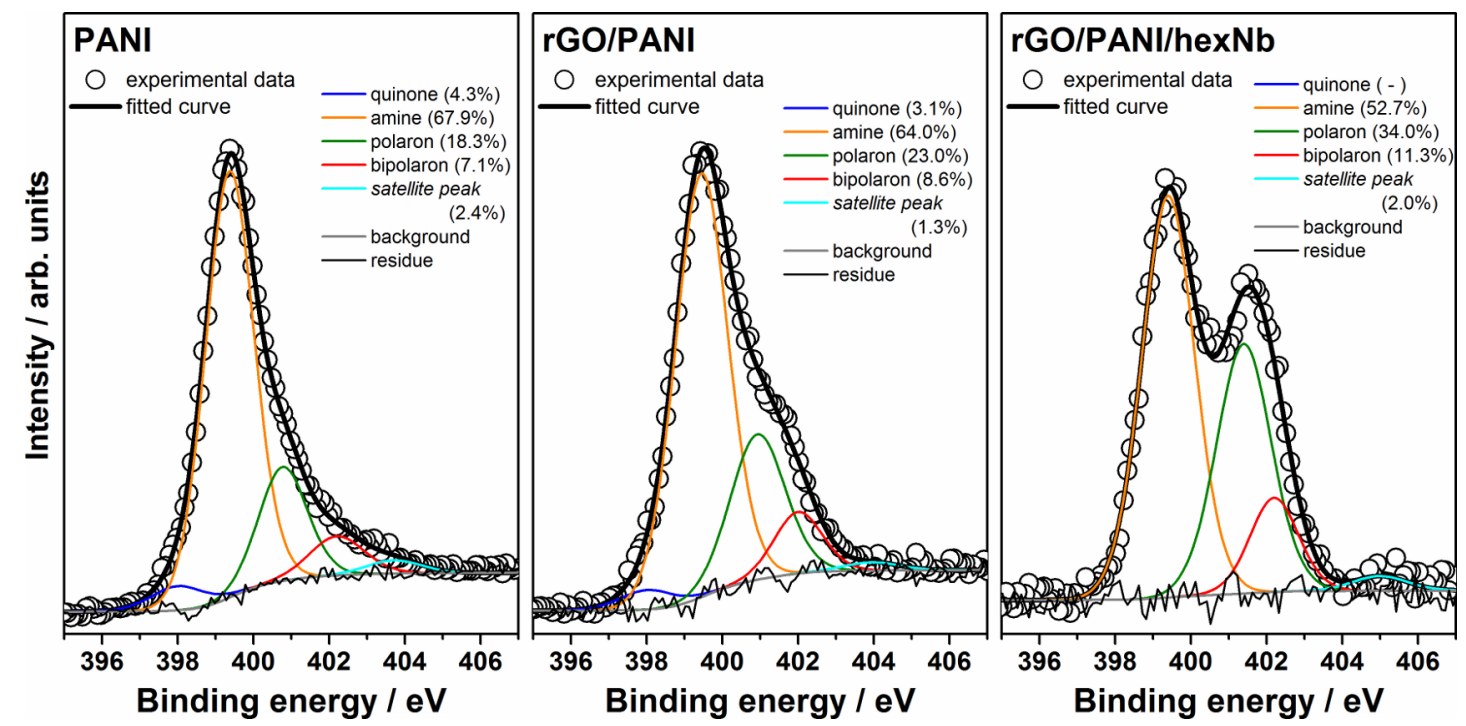

Figure 5: XPS spectra at $\mathrm{N}$ 1s core level of PANI and nanocomposites rGO/PANI and rGO/PANI/hexNb.

the ternary nanocomposite (polaron/bipolaron $=3.0$ ), compared to PANI (2.6) and the binary nanocomposite (2.7). This indicates that the formation of polaron segments in the PANI chains is further induced by the interaction with $\mathrm{rGO}$ and hexNb components. This behaviour of high polaron formation induced by hexNb nanoparticles has been reported by us before [7]. The results of XPS spectra at N 1s core level are supported by resonance Raman spectroscopy, as shown below.

The structural characterisation of PANI in the nanocomposites was also performed by Raman spectroscopy, as presented in Figure 6. Raman bands in the spectra of rGO/PANI and rGO/ $\mathrm{PANI} / \mathrm{hexNb}$ at $632.8 \mathrm{~nm}$ excitation wavelength are mainly attributed to the polymer due to resonance effects with the polaronic/bipolaronic electronic transitions of PANI, and the high content of polymer in these materials [55-58]. The spectra presented in Figure 6a show the characteristic features of the emeraldine salt form (doped polymer) for all samples. However, comparing the spectra of the nanocomposites with the neat polymer (PANI), the bands at ca. 1336 and ca. $1600 \mathrm{~cm}^{-1}$ for the hybrid materials present higher relative intensities. These results can be attributed to the contribution of rGO bands $[35,36,45,46,48,50,51,59,60]$, and changes in the doping state of the polymer due to interaction with the other components.

Figure $6 \mathrm{~b}$ presents the curve fitting results in the range of 1450-1550 $\mathrm{cm}^{-1}$. The component at lower wavenumber (red curve) is assigned to bipolaron segments, whereas the component at higher wavenumber (green curve) is assigned to polaron segments. The comparison of the results for PANI and $\mathrm{rGO} /$ PANI shows the increase of the relative intensity of the polaron

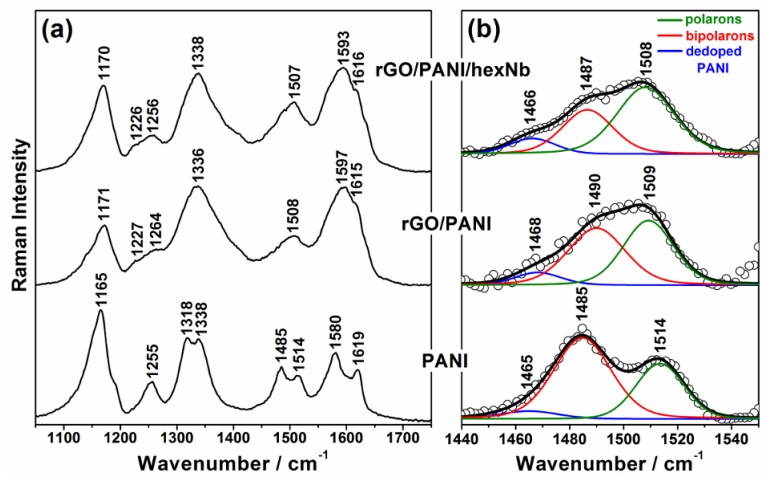

Figure 6: (a) Raman spectra $\left(\lambda_{0}=632.8 \mathrm{~nm}\right)$ of PANI, rGO/PANI and $\mathrm{rGO} / \mathrm{PANI} / \mathrm{hexNb}$ in the range of $1050-1750 \mathrm{~cm}^{-1}$ and (b) curve fitting for bipolaron and polaron components in the range of $1440-1550 \mathrm{~cm}^{-1}$

component, which indicates a conversion of bipolarons to polarons in the presence of the rGO flakes. Moreover, Figure $6 \mathrm{~b}$ shows that the relative contribution from the polaron segments is further increased for the $\mathrm{rGO} / \mathrm{PANI} /$ hexNb sample, which suggests a higher formation of polarons induced by hexNb nanoparticles. These results are in agreement with XPS data previously discussed and reports of spectroscopic characterisation of PANI-based materials [6,7,26,61], which suggested a high doping level of PANI induced by conformational changes in the polymeric backbone.

Figure 7 presents the $\mathrm{CV}$ curves obtained for PANI, rGO, rGO/ $\mathrm{PANI}, \mathrm{PANI} / \mathrm{hexNb}$ and $\mathrm{rGO} / \mathrm{PANI} / \mathrm{hexNb}$ in $1 \mathrm{~mol} \cdot \mathrm{L}^{-1}$ 


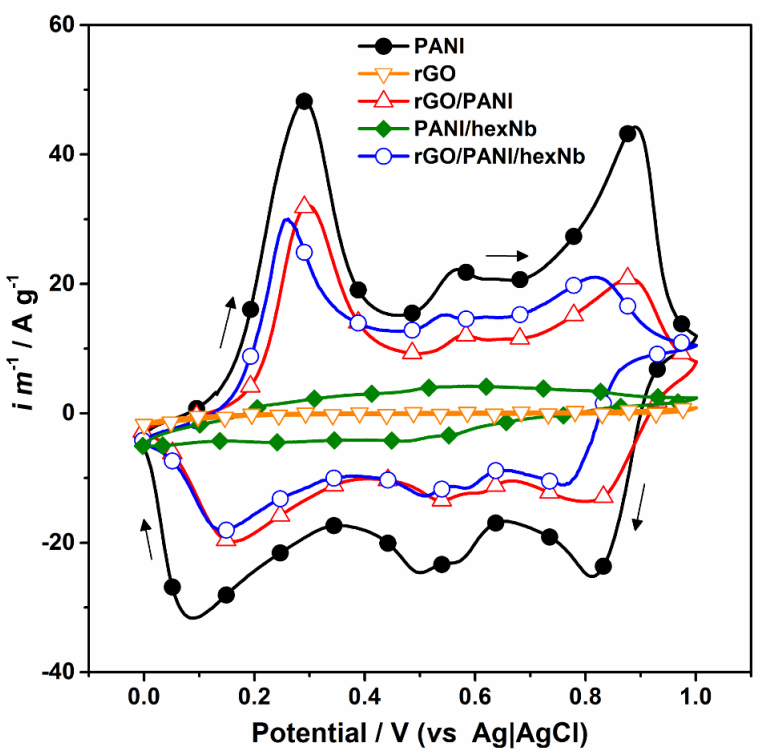

Figure 7: CV curves of PANI, rGO, rGO/PANI , PANI/hexNb and rGO/ $\mathrm{PANI} / \mathrm{hexNb}$ at $25 \mathrm{mV} \cdot \mathrm{s}^{-1}$ scan rate. Electrolyte solution: $1 \mathrm{~mol} \cdot \mathrm{L}^{-1}$ sulfuric acid.

sulfuric acid solution. For PANI sample and nanocomposites, Figure 7 shows the characteristic redox peaks at ca. $+0.30 \mathrm{~V}$ $(+0.10 \mathrm{~V})$, attributed to the oxidation (reduction) processes between leucoemeraldine and emeraldine salt states, and the peaks at potentials above $+0.75 \mathrm{~V}$ attributed to the transitions between emeraldine salt and pernigraniline states [62-64]. The peaks at intermediate potentials (between +0.40 and $+0.70 \mathrm{~V}$ ) are attributed to oxidative electrochemical reactions initiated when PANI is cycled at higher potentials than $+0.70 \mathrm{~V}$. The CV curve for rGO sample confirms the absence of significant faradaic processes due to a very low current profile. For the $\mathrm{PANI} / \mathrm{hexNb}$ reference sample, the CV curve presents less defined oxidation (reduction) peaks at $+0.20 \mathrm{~V}(+0.25 \mathrm{~V})$ and $+0.80 \mathrm{~V}(+0.75 \mathrm{~V})$, in addition to intermediate peaks in the range of $+0.40-0.60 \mathrm{~V}$. This low current potentiodynamic profile is attributed to the absence of faradaic processes in the hexaniobate component, which also affects polyaniline redox processes under the experimental conditions. The comparison of the curves of rGO/PANI and rGO/PANI/hexNb in Figure 7 indicates similar areas, although neat PANI still presents the highest current profile. The specific capacitances calculated for PANI, binary $\mathrm{rGO} / \mathrm{PANI}$ and ternary $\mathrm{rGO} / \mathrm{PANI} / \mathrm{hexNb}$ are 880,515 and $564 \mathrm{~F} \cdot \mathrm{g}^{-1}$, respectively, whereas for the binary $\mathrm{PANI} / \mathrm{h}$ exNb reference sample it is $87 \mathrm{~F} \cdot \mathrm{g}^{-1}$. The difference between the specific capacitances of neat PANI and nanocomposites can be attributed to the presence of rGO. Surprisingly, the comparison of binary and ternary nanocomposites perfor- mances indicates that hexNb nanoparticles improve the electrochemical properties of the ternary material under the experimental conditions. Considering that $\mathrm{PANI} /$ hexNb sample presents a lower current profile, the observed improvement for $\mathrm{rGO} / \mathrm{PANI} /$ hexNb indicates a synergetic effect, which is attributed to strong interactions between the components in the ternary nanocomposite. These results are in accordance with structural characterisation presented in this paper, which showed an enhancement of the polymer doping state, due to the secondary doping of the PANI backbone in the rGO/PANI/ hexNb nanocomposite. The capacitances of the new nanocomposite presented in this work are comparable to other materials based on graphene oxide/polyaniline reported in literature, which present typical capacitances ranging from 350 to $800 \mathrm{~F} \cdot \mathrm{g}^{-1}[4,22,49,65]$. Although this result does not stimulate studies focusing on the application of $\mathrm{rGO} / \mathrm{PANI} / \mathrm{h}$ exNb in energy-storage devices, the thin film obtained by dropcasting has potential to be explored for other purposes since the amount of charge carriers is increased in the ternary nanocomposite.

\section{Conclusion}

In this paper we reported the development a new nanocomposite composed of reduced graphene oxide ( $\mathrm{rGO}$ ), polyaniline (PANI) and hexaniobate (hexNb) prepared by mixing the colloidal dispersions of the components. Morphological characterisation showed an interesting architecture at the nanoscale range of rGO flakes coated with PANI and decorated with hexNb nanoparticles. Such organization was attributed to the good stability of the dispersion, which does not present major aggregation and phase separation. The dispersions of the ternary $\mathrm{rGO} / \mathrm{PANI} /$ hexNb sample can be deposited on surfaces by spincoating or dropcasting. Structural characterisation by XPS spectroscopy indicated an intermediate reduction degree for the rGO component, and a high doping degree of the PANI chains consistent with secondary doping of the polymer. Electrochemical studies by cyclic voltammetry showed that the capacitance of the ternary nanocomposite is higher compared to the binary composites. Such results are attributed to cooperative effects of PANI chains with rGO flakes and hexNb nanoscrolls promoted by the nanostructured architecture, resulting in a high doping degree of polymeric chains. The interesting chemical versatility and significant interactions between the components are attractive features for applications that require chemically functionalised materials in the film form, such as sensing or corrosion protection.

\section{Experimental Materials}

Precursor graphite flakes (NGS Naturgraphit GmbH, $300 \mu \mathrm{m}$ flake size) were used as received. Aniline (Merck) was distilled under reduced pressure prior to use. Niobium pentoxide 
(Companhia Brasileira de Metalurgia e Mineração, CBMM) was used as received. All other chemicals (Sigma-Aldrich) were also used as received.

\section{Preparation of graphene oxide and reduced graphene oxide}

Graphene oxide was prepared by graphite oxidation according to a modified Hummers method [66,67]. The viscous gel-like dispersion of graphite oxide obtained after oxidation and purification (centrifugation and washing) was diluted with deionized water and the resulting dispersions were high-shear mixed at $7000 \mathrm{rpm}$ for four times (15 min each). This procedure was used to avoid thermal degradation of the sample. The GO particles prepared by this method present flake sizes ranging from 5 to $30 \mu \mathrm{m}[14,17]$, which are remarkably larger in comparison to GO reported in literature obtained by sonication (less than $10 \mu \mathrm{m})[34,35,42-44,67]$. Reduced graphene oxide was prepared by chemical reduction of GO in $0.25 \mathrm{mg} \cdot \mathrm{mL}^{-1}$ dispersions with hydrazine and ammonia solution at $25^{\circ} \mathrm{C}$ for 7 days. The resulting rGO dispersion presents suitable stability for the preparation of the nanocomposites. This sample is labelled as "rGO-25" herein. A reference rGO sample was also prepared by GO reduction under similar conditions as rGO-25, but at $80{ }^{\circ} \mathrm{C}$ and $3 \mathrm{~h}$ of reaction. This sample is labelled as "rGO- $80^{\prime}$ " herein. Detailed experimental procedures are available in Supporting Information File 1.

\section{Preparation of polyaniline and hexaniobate precursor dispersions}

Dispersions of polyaniline in water/ $N, N$-dimethylacetamide (DMA) were prepared as described in the literature $[6,50,68]$. The concentration of PANI, the water/DMA volume ratio and the $\mathrm{pH}$ values of the dispersions were adjusted considering the procedure for the preparation of nanocomposites. Hexaniobate (hexNb) was prepared as reported previously [6], which results in colloidal dispersions of scrolled hexaniobate nanoparticles, called hexaniobate nanoscrolls. Detailed experimental procedures are available in Supporting Information File 1.

\section{Preparation of the binary (rGO/PANI) and ternary (rGO/PANI/hexNb) nanocomposites}

For preparation of the $\mathrm{rGO} / \mathrm{PANI}$ nanocomposite, $35 \mathrm{~mL}$ of hydrochloric acid solution ( $\mathrm{pH}$ 3) was slowly added to $25 \mathrm{~mL}$ of PANI solution in DMA $\left(2.8 \mathrm{mg} \cdot \mathrm{mL}^{-1}\right)$, and the $\mathrm{pH}$ value of the resulting dispersion was carefully adjusted to 3 by adding $1 \mathrm{~mol} \cdot \mathrm{L}^{-1} \mathrm{HCl}$. Then, $70 \mathrm{~mL}$ of $\mathrm{rGO}-25$ dispersion $\left(0.25 \mathrm{mg} \cdot \mathrm{mL}^{-1}, \mathrm{pH} 8.7\right)$ was slowly added to PANI dispersion along with $1 \mathrm{~mol} \cdot \mathrm{L}^{-1} \mathrm{HCl}$ to maintain the $\mathrm{pH}$ value of the $\mathrm{PANI} / \mathrm{rGO}$ mixture in a range of 2.7-3.0. After addition of $\mathrm{rGO}$ dispersion, the $\mathrm{pH}$ value was adjusted to 2.6 and the mixture was stirred for 5 days at $20^{\circ} \mathrm{C}$. The total volume of $\mathrm{HCl}$ solu- tion used for the preparation of rGO/PANI was $8 \mathrm{~mL}$. The $\mathrm{rGO} /$ $\mathrm{PANI} /$ hexNb nanocomposite was prepared by slowly adding $40 \mathrm{~mL}$ of hexNb dispersion $\left(1.13 \mathrm{mg} \cdot \mathrm{mL}^{-1}, \mathrm{pH} 6.8\right)$ to $45 \mathrm{~mL}$ of $\mathrm{rGO} / \mathrm{PANI}$ mixture. After mixing hexNb and $\mathrm{rGO} / \mathrm{PANI}$ dispersions, $1 \mathrm{~mol} \cdot \mathrm{L}^{-1} \mathrm{HCl}$ solution was added to re-adjust the $\mathrm{pH}$ value to 2.6, and the $\mathrm{rGO} / \mathrm{PANI} /$ hexNb mixture was stirred for 2 days at $20^{\circ} \mathrm{C}$. A PANI/hexNb reference sample was prepared with the same $\mathrm{PANI} /$ hexNb weight ratio as the ternary nanocomposite. rGO/PANI, rGO/PANI/hexNb and PANI/ hexNb samples were further processed by centrifugation/ washing cycles (14000 rpm, $20 \mathrm{~min}$ and $\mathrm{HCl}$ solution $\mathrm{pH} 2.6$ ) to obtain dispersions of a total concentration of $1.0 \mathrm{mg} \cdot \mathrm{mL}^{-1}$.

\section{Characterization}

The AFM images were recorded with a Bruker Dimension FastScan probe microscope, operating in tapping mode, with aluminium-coated Si tips (Bruker). Samples were prepared by spincoating the dispersions of $\mathrm{rGO}, \mathrm{rGO} / \mathrm{PANI}$ and $\mathrm{rGO} / \mathrm{PANI} /$ hex $\mathrm{Nb}\left(1.0 \mathrm{mg} \cdot \mathrm{mL}^{-1}\right.$ total concentration $)$ on $\mathrm{Si} / \mathrm{SiO}_{2}$ substrates at $3000 \mathrm{rpm}\left(300 \mathrm{rpm} \cdot \mathrm{s}^{-1}\right.$ acceleration, $\left.90 \mathrm{~s}\right)$. In order to properly compare the AFM images, processing was performed with the aid of WSxM software (version 4.0 Beta 7.0) [69]. Height profiles were measured with the aid of WSxM software for the processed images and the surface roughness of the particles will be discussed by means of the root mean square (RMS) values calculated from the height profiles.

XPS spectra were acquired on a SPECS custom-built system composed of a Phobios 150 hemispherical electron analyser with $1 \mathrm{D}$ detector. The X-ray source was a microfocus monochromated Al K $\alpha(1486.6 \mathrm{eV})$ source. Spectra were collected with pass energy of $20 \mathrm{eV}$, and the combined ultimate resolution is $0.5 \mathrm{eV}$ with $\mathrm{X}$-ray source and $20 \mathrm{eV}$ pass, as measured from $\mathrm{Ag} 3 \mathrm{~d}$. The samples were prepared by dropcasting the dispersions $\left(1.0 \mathrm{mg} \cdot \mathrm{mL}^{-1}\right.$ total concentration) on $1 \mathrm{~cm}^{2}$ square Si substrates and drying under reduced pressure at room temperature. Data analysis was performed with the aid of CasaXPS software (version 2.3.16 PR 1.6). Peak fitting for high-resolution spectra (C 1s and $\mathrm{N}$ 1s core levels) was performed by applying tight constrains for binding energy range, full width at half maximum (FWHM) and shape of components, based on a comprehensive assessment of the literature [13,34,39,40,44-47]. Further details of the fitting parameters are presented in Supporting Information File 1.

Raman spectra were obtained on a Renishaw Raman imaging microscope (inVia) equipped with a Leica microscope and a CCD detector. Spectra were excited at $632.8 \mathrm{~nm}$ (RL633 Renishaw Class 3B HeNe laser, $12 \mathrm{~mW}$ ) and samples were focused with a $50 \times$ lens. The laser power was kept below $50 \mu \mathrm{W}$ to avoid thermal degradation of the samples. For better 
comparison of the relative intensities, spectral baselines were subtracted.

The electrochemical performance of the samples was evaluated by cyclic voltammetry $(\mathrm{CV})$ at $25 \mathrm{mV} \cdot \mathrm{s}^{-1}$ scan rate using a $\mu$ AutolabIII/FRA2 potentiostat/galvanostat (Metrohm Autolab). The measurements were performed with $\mathrm{Ag} / \mathrm{AgCl}$ and $\mathrm{Pt}$ coil as reference and counter electrodes, respectively, and $1 \mathrm{~mol} \cdot \mathrm{L}^{-1}$ sulfuric acid as electrolyte solution. The working electrodes were prepared by dropcasting the samples on glass $/ \mathrm{Cr}(5 \mathrm{~nm}) /$ $\mathrm{Au}(60 \mathrm{~nm})$ substrates prepared by thermal evaporation.

\section{Supporting Information}

\section{Supporting Information File 1}

Additional experimental data.

[https://www.beilstein-journals.org/bjnano/content/ supplementary/2190-4286-9-272-S1.pdf]

\section{Acknowledgements}

The authors acknowledge the Brazilian agencies FAPESP (projects 2014/05048-4, 2013/03013-6, 2012/13119-3 and 2011/50318-1) and CNPq (project 302792/2015-5) for fellowships and financial support. The authors are grateful for funding from the Bill \& Melinda Gates Foundation Grand Challenge Explorations scheme and Engineering and Physical Sciences Research Council EPSRC (grant EP/G035954/1). They also thank Companhia Brasileira de Metalurgia e Mineração (CBMM) for providing $\mathrm{Nb}_{2} \mathrm{O}_{5}$ sample.

\section{ORCID ${ }^{\circledR}$ iDs}

Claudio H. B. Silva - https://orcid.org/0000-0003-4331-3755 Maria lliut - https://orcid.org/0000-0003-0786-6408 Christopher Muryn - https://orcid.org/0000-0002-4281-9183 Christian Berger - https://orcid.org/0000-0001-5252-6328 Vera R. L. Constantino - https://orcid.org/0000-0001-9276-7329 Marcia L. A. Temperini - https://orcid.org/0000-0003-4655-6891 Aravind Vijayaraghavan - https://orcid.org/0000-0001-8289-2337

\section{References}

1. Zhang, Q.; Uchaker, E.; Candelaria, S. L.; Cao, G. Chem. Soc. Rev. 2013, 42, 3127-3171. doi:10.1039/c3cs00009e

2. Huang, X.; Qi, X.; Boey, F.; Zhang, H. Chem. Soc. Rev. 2012, 41, 666-686. doi:10.1039/c1cs15078b

3. Kim, S.; Le, T.-H.; Park, C. S.; Park, G.; Kim, K. H.; Kim, S.; Kwon, O. S.; Lim, G. T.; Yoon, H. Sci. Rep. 2017, 7, No. 15184. doi:10.1038/s41598-017-15552-w

4. Xia, X.; Hao, Q.; Lei, W.; Wang, W.; Wang, H.; Wang, X. J. Mater. Chem. 2012, 22, 8314-8320. doi:10.1039/c2jm16216d

5. Radhakrishnan, S.; Krishnamoorthy, K.; Sekar, C.; Wilson, J.; Kim, S. J. Chem. Eng. J. 2015, 259, 594-602. doi:10.1016/j.cej.2014.08.047
6. Silva, C. H. B.; Galiote, N. A.; Huguenin, F.; Teixeira-Neto, É.; Constantino, V. R. L.; Temperini, M. L. A. J. Mater. Chem. 2012, 22, 14052-14060. doi:10.1039/c2jm31531a

7. Silva, C. H. B.; Da Costa Ferreira, A. M.; Constantino, V. R. L.; Temperini, M. L. A. J. Mater. Chem. A 2014, 2, 8205-8214. doi:10.1039/c4ta00737a

8. Wang, L.; Lu, X.; Lei, S.; Song, Y. J. Mater. Chem. A 2014, 2, 4491-4509. doi:10.1039/c3ta13462h

9. Lei, W.; Si, W.; Xu, Y.; Gu, Z.; Hao, Q. Microchim. Acta 2014, 181, 707-722. doi:10.1007/s00604-014-1160-6

10. Geim, A. K.; Novoselov, K. S. Nat. Mater. 2007, 6, 183-191. doi:10.1038/nmat1849

11. Rao, C. N. R.; Sood, A. K.; Subrahmanyam, K. S.; Govindaraj, A. Angew. Chem., Int. Ed. 2009, 48, 7752-7777. doi:10.1002/anie.200901678

12. Dreyer, D. R.; Park, S.; Bielawski, C. W.; Ruoff, R. S. Chem. Soc. Rev. 2010, 39, 228-240. doi:10.1039/b917103g

13. Rourke, J. P.; Pandey, P. A.; Moore, J. J.; Bates, M.; Kinloch, I. A.; Young, R. J.; Wilson, N. R. Angew. Chem., Int. Ed. 2011, 50, 3173-3177. doi:10.1002/anie.201007520

14. Fiorillo, M.; Verre, A. F.; lliut, M.; Peiris-Pagés, M.; Ozsvari, B.; Gandara, R.; Cappello, A. R.; Sotgia, F.; Vijayaraghavan, A.; Lisanti, M. P. Oncotarget 2015, 6, 3553-3562. doi:10.18632/oncotarget.3348

15. Lee, C.; Wei, X.; Kysar, J. W.; Hone, J. Science 2008, 321, 385-388. doi:10.1126/science.1157996

16. Iliut, M.; Silva, C.; Herrick, S.; McGlothlin, M.; Vijayaraghavan, A. Carbon 2016, 106, 228-232. doi:10.1016/j.carbon.2016.05.032

17. Garcia-Alegria, E.; lliut, M.; Stefanska, M.; Silva, C.; Heeg, S.; Kimber, S. J.; Kouskoff, V.; Lacaud, G.; Vijayaraghavan, A.; Batta, K. Sci. Rep. 2016, 6, No. 25917. doi:10.1038/srep25917

18. Janata, J.; Josowicz, M. Nat. Mater. 2003, 2, 19-24. doi:10.1038/nmat768

19. Virji, S.; Huang, J.; Kaner, R. B.; Weiller, B. H. Nano Lett. 2004, 4, 491-496. doi:10.1021/nl035122e

20. Tseng, R. J.; Huang, J.; Ouyang, J.; Kaner, R. B.; Yang, Y. Nano Lett. 2005, 5, 1077-1080. doi:10.1021/nl050587I

21. Yang, Y.; Ouyang, J.; Ma, L.; Tseng, R. J.-H.; Chu, C.-W. Adv. Funct. Mater. 2006, 16, 1001-1014. doi:10.1002/adfm.200500429

22. Xu, Y.; Tao, Y.; Zheng, X.; Ma, H.; Luo, J.; Kang, F.; Yang, Q.-H. Adv. Mater. 2015, 27, 8082-8087. doi:10.1002/adma.201504151

23. Rego, L. S.; Antonio, J. L. S.; Silva, C. H. B.; Nobrega, M. M.; Temperini, M. L. A.; Torresi, R. M.; de Torresi, S. I. C. J. Solid State Electrochem. 2016, 20, 983-991. doi:10.1007/s10008-015-2952-2

24. Heeger, A. J. Angew. Chem., Int. Ed. 2001, 40, 2591-2611. doi:10.1002/1521-3773(20010716)40:14<2591::aid-anie2591>3.0.co;20

25. Stafström, S.; Brédas, J. L.; Epstein, A. J.; Woo, H. S.; Tanner, D. B. Huan, W. S.; MacDiarmid, A. G. Phys. Rev. Lett. 1987, 59, 1464-1467. doi:10.1103/physrevlett.59.1464

26. Izumi, C. M. S.; Constantino, V. R. L.; Temperini, M. L. A. J. Nanosci. Nanotechnol. 2008, 8, 1782-1789.

27. Nobrega, M. M.; Martins, V. L.; Torresi, R. M.; Temperini, M. L. A. J. Phys. Chem. C 2014, 118, 4267-4274. doi:10.1021/jp4120755

28. Gasperin, M.; Le Bihan, M. T. J. Solid State Chem. 1982, 43, 346-353. doi:10.1016/0022-4596(82)90251-1

29. Bizeto, M. A.; Constantino, V. R. L. Mater. Res. Bull. 2004, 39 , 1729-1736. doi:10.1016/j.materresbull.2004.05.001 
30. Takagaki, A.; Sugisawa, M.; Lu, D.; Kondo, J. N.; Hara, M.; Domen, K.; Hayashi, S. J. Am. Chem. Soc. 2003, 125, 5479-5485. doi:10.1021/ja034085q

31. Dias, A. S.; Lima, S.; Carriazo, D.; Rives, V.; Pillinger, M.; Valente, A. A. J. Catal. 2006, 244, 230-237. doi:10.1016/j.jcat.2006.09.010

32. Bizeto, M. A.; Shiguihara, A. L.; Constantino, V. R. L. J. Mater. Chem. 2009, 19, 2512-2525. doi:10.1039/b821435b

33. Shiguihara, A. L.; Bizeto, M. A.; Constantino, V. R. L. Colloids Surf., A 2007, 295, 123-129. doi:10.1016/j.colsurfa.2006.08.040

34. Stankovich, S.; Dikin, D. A.; Piner, R. D.; Kohlhaas, K. A.; Kleinhammes, A.; Jia, Y.; Nguyen, S. T.; Ruoff, R. S. Carbon 2007, 45, 1558-1565. doi:10.1016/j.carbon.2007.02.034

35. Fernández-Merino, M. J.; Guardia, L.; Paredes, J. I.; Villar-Rodil, S.; Solis-Fernández, P.; Martínez-Alonso, A.; Tascón, J. M. D. J. Phys. Chem. C 2010, 114, 6426-6432. doi:10.1021/jp100603h

36. Huan, J. Pure Appl. Chem. 2006, 78, 15-27. doi:10.1351/pac200678010015

37. Bizeto, M. A.; Constantino, V. R. L. Microporous Mesoporous Mater. 2005, 83, 212-218. doi:10.1016/j.micromeso.2005.04.013

38. Saupe, G. B.; Waraksa, C. C.; Kim, H.-N.; Han, Y. J.; Kaschak, D. M.; Skinner, D. M.; Mallouk, T. E. Chem. Mater. 2000, 12, 1556-1562. doi:10.1021/cm981136n

39. Koinuma, M.; Tateishi, H.; Hatakeyama, K.; Miyamoto, S.; Ogata, C.; Funatsu, A.; Taniguchi, T.; Matsumoto, Y. Chem. Lett. 2013, 42, 924-926. doi:10.1246/cl.130152

40. Jeong, H.-K.; Lee, Y. P.; Lahaye, R. J. W. E.; Park, M.-H.; An, K. H.; Kim, I. J.; Yan, C.-W.; Park, C. Y.; Ruoff, R. S.; Lee, Y. H. J. Am. Chem. Soc. 2008, 130, 1362-1366. doi:10.1021/ja076473o

41. Leiro, J. A.; Heinonen, M. H.; Laiho, T.; Batirev, I. G. J. Electron Spectrosc. Relat. Phenom. 2003, 128, 205-213. doi:10.1016/s0368-2048(02)00284-0

42. Marcano, D. C.; Kosynkin, D. V.; Berlin, J. M.; Sinitskii, A.; Sun, Z.; Slesarev, A.; Alemany, L. B.; Lu, W.; Tour, J. M. ACS Nano 2010, 4, 4806-4814. doi:10.1021/nn1006368

43. Park, S.; An, J.; Piner, R. D.; Jung, I.; Yang, D.; Velamakanni, A.; Nguyen, S. T.; Ruoff, R. S. Chem. Mater. 2008, 20, 6592-6594. doi:10.1021/cm801932u

44. Rani, J. R.; Lim, J.; Oh, J.; Kim, J.-W.; Shin, H. S.; Kim, J. H.; Lee, S.; Jun, S. C. J. Phys. Chem. C 2012, 116, 19010-19017. doi:10.1021/jp3050302

45. Hsiao, M.-C.; Liao, S.-H.; Yen, M.-Y.; Teng, C.-C.; Lee, S.-H.; Pu, N.-W.; Wang, C.-A.; Sung, Y.; Ger, M.-D.; Ma, C.-C. M.; Hsiao, M.-H. J. Mater. Chem. 2010, 20, 8496-8505. doi:10.1039/c0jm01679a

46. Ren, P.-G.; Yan, D.-X.; Ji, X.; Chen, T.; Li, Z.-M. Nanotechnology 2011, 22, 055705. doi:10.1088/0957-4484/22/5/055705

47. Bagri, A.; Mattevi, C.; Acik, M.; Chabal, Y. J.; Chhowalla, M.; Shenoy, V. B. Nat. Chem. 2010, 2, 581-587. doi:10.1038/nchem.686

48. Krishnamoorthy, K.; Veerapandian, M.; Yun, K.; Kim, S.-J. Carbon 2013, 53, 38-49. doi:10.1016/j.carbon.2012.10.013

49. Jianhua, L.; Junwei, A.; Yecheng, Z.; Yuxiao, M.; Mengliu, L.; Mei, Y.; Songmei, L. ACS Appl. Mater. Interfaces 2012, 4, 2870-2876. doi:10.1021/am300640y

50. Yang, D.; Velamakanni, A.; Bozoklu, G.; Park, S.; Stoller, M.; Piner, R. D.; Stankovich, S.; Jung, I.; Field, D. A.; Ventrice, C. A., Jr.; Ruoff, R. S. Carbon 2009, 47, 145-152. doi:10.1016/j.carbon.2008.09.045

51. Bo, Z.; Shuai, X.; Mao, S.; Yang, H.; Qian, J.; Chen, J.; Yan, J.; Cen, K. Sci. Rep. 2014, 4, No. 4684. doi:10.1038/srep04684
52. Monkman, A. P.; Stevens, G. C.; Bloor, D. J. Phys. D: Appl. Phys. 1991, 24, 738-749. doi:10.1088/0022-3727/24/5/017

53. Tan, K. L.; Tan, B. T. G.; Kang, E. T.; Neoh, K. G. J. Chem. Phys. 1991, 94, 5382-5388. doi:10.1063/1.460524

54. Kang, E. T.; Neoh, K. G.; Tan, K. L. Surf. Interface Anal. 1993, 20 , 833-840. doi:10.1002/sia.740201006

55. Zeng, X.-R.; Ko, T.-M. Polymer 1998, 39, 1187-1195. doi:10.1016/s0032-3861(97)00381-9

56. Furukawa, Y.; Ueda, F.; Hyodo, Y.; Harada, I.; Nakajima, T.; Kawagoe, T. Macromolecules 1988, 21, 1297-1305. doi:10.1021/ma00183a020

57. Louarn, G.; Lapkowski, M.; Quillard, S.; Pron, A.; Buisson, J. P.; Lefrant, S. J. Phys. Chem. 1996, 100, 6998-7006. doi:10.1021/jp953387e

58. Cochet, M.; Louarn, G.; Quillard, S.; Buisson, J. P.; Lefrant, S. J. Raman Spectrosc. 2000, 31, 1041-1049. doi:10.1002/1097-4555(200012)31:12<1041::aid-jrs641>3.0.co;2-r

59. Boyer, M. I.; Quillard, S.; Louarn, G.; Froyer, G.; Lefrant, S. J. Phys. Chem. B 2000, 104, 8952-8961. doi:10.1021/jp000946v

60. Eda, G.; Fanchini, G.; Chhowalla, M. Nat. Nanotechnol. 2008, 3, 270-274. doi:10.1038/nnano.2008.83

61. Iliut, M.; Leordean, C.; Canpean, V.; Teodorescu, C.-M.; Astilean, S. J. Mater. Chem. C 2013, 1, 4094-4104. doi:10.1039/c3tc30177j

62. da Silva, J. E. P.; Temperini, M. L. A.; de Torresi, S. I. C. Electrochim. Acta 1999, 44, 1887-1891. doi:10.1016/s0013-4686(98)00330-2

63. Huang, W. S.; Humphrey, B. D.; MacDiarmid, A. G. J. Chem. Soc., Faraday Trans. 1 1986, 82, 2385-2400. doi:10.1039/f19868202385

64. Geniès, E. M.; Lapkowski, M.; Penneau, J. F. J. Electroanal. Chem. Interfacial Electrochem. 1988, 249, 97-107. doi:10.1016/0022-0728(88)80351-6

65. Kobayashi, T.; Yoneyama, H.; Tamura, H. J. Electroanal. Chem. Interfacial Electrochem. 1984, 161, 419-423. doi:10.1016/s0022-0728(84)80201-6

66. Xiong, P.; Hu, C.; Fan, Y.; Zhang, W.; Zhu, J.; Wang, X. J. Power Sources 2014, 266, 384-392. doi:10.1016/j.jpowsour.2014.05.048

67. Hummers, W. S., Jr.; Offeman, R. E. J. Am. Chem. Soc. 1958, 80, 1339. doi:10.1021/ja01539a017

68. Cheung, J. H.; Stockton, W. B.; Rubner, M. F. Macromolecules 1997, 30, 2712-2716. doi:10.1021/ma970047d

69. Horcas, I.; Fernández, R.; Gómez-Rodríguez, J. M.; Colchero, J.; Gómez-Herrero, J.; Baro, A. M. Rev. Sci. Instrum. 2007, 78, No. 013705 . doi: $10.1063 / 1.2432410$ 


\section{License and Terms}

This is an Open Access article under the terms of the Creative Commons Attribution License (http://creativecommons.org/licenses/by/4.0). Please note that the reuse, redistribution and reproduction in particular requires that the authors and source are credited.

The license is subject to the Beilstein Journal of Nanotechnology terms and conditions:

(https://www.beilstein-journals.org/bjnano)

The definitive version of this article is the electronic one which can be found at:

doi:10.3762/bjnano.9.272 